\title{
Probiotic potential and biochemical and technological properties of Lactococcus lactis ssp. lactis strains isolated from raw milk and kefir grains
}

\section{Oktay Yerlikaya*}

Ege University, Faculty of Agriculture, Department of Dairy Technology, 35100, Bornova, İzmir, Turkey

\begin{abstract}
Lactococcus lactis ssp. lactis is one of the most important starter bacteria used in dairy technology and it is of great economic importance because of its use in the production of dairy products, including cheese, butter, cream, and fermented milks. Numerous studies have evaluated the biochemical and probiotic properties of lactococci; however, limited studies on the probiotic characteristics of lactococci were conducted using strains originating from raw milk and dairy products. Characterizing the probiotic properties of strains isolated from raw milk and fermented milk products is important in terms of selecting starter culture strains for the production of functional dairy products. In this study, biochemical properties (including antibiotic sensitivity, lipolytic activity, amino acid decarboxylation, antioxidant activity) and probiotic properties (including antimicrobial activity, growth in the presence of bile salts, bile salts deconjugation, and hydrophobicity) of 14 Lactococcus lactis strains isolated from raw milk and kefir grains were investigated. Strains originating from kefir grains had better characteristics in terms of antimicrobial activity and bile salt deconjugation, whereas strains from raw milk had better hydrophobicity and antioxidant activity characteristics. None of the strains were able to grow in the presence of bile salt and did not show amino acid decarboxylation or lipolytic activities. Biochemical and probiotic properties of $L$. lactis strains varied depending on the strain and some of these strains could be used as functional cultures depending on their properties. However, these strains did not possess all of the properties required to meet the definition of a probiotic.
\end{abstract}

Received April 27, 2018.

Accepted September 13, 2018.

*Corresponding author: oktay.yerlikaya@ege.edu.tr
Key words: Lactococcus lactis ssp. lactis, dairy starter, probiotics, kefir grain, raw milk

\section{INTRODUCTION}

Lactic acid bacteria (LAB) are used in the production of many fermented food products. They are grampositive, facultative anaerobic, catalase-negative, and motile. The LAB do not constitute cytochrome and do not form spores. They belong to the order Eubacteriales under Streptococcaceae and Lactobacillaceae families. The genera that comprise LAB are Lactobacillus, Lactococcus, Bifidobacterium, Tetragonococcus, Vagococcus, Weissella, Streptococcus, Leuconostoc, Aerococcus, Oenococcus, Carnobacterium, Enterococcus, Sporolactobacillus, and Pediococcus. The LAB play important roles in ensuring the protection and safety of dairy products through production of antimicrobial agents including lactic acid, diacetyl, hydrogen peroxide, and bacteriocins (Salminen et al., 1993; Axelsson and Ahrné, 2000). Bacteriocins, which have the potential to serve as food preservatives, have been identified in dairy starter cultures (Kojic et al., 2006; Balciunas et al., 2013).

Strains of the genus Lactococcus have cocci morphologies and form single cocci pairs or short chain formations $(0.5-1.5 \mu \mathrm{m})$ in their growth medium. Their optimum growth temperature is $30^{\circ} \mathrm{C}$ and they can grow between $10^{\circ} \mathrm{C}$ and $45^{\circ} \mathrm{C}$. Their ability to grow above $40^{\circ} \mathrm{C}$, to grow at higher salt concentrations ( $>4 \%$ sodium chloride), and to produce acid from different sugars (arabinose, lactose, mannitol, and raffinose) vary depending on the species (Schlegel, 1997; Furet et al., 2004; Khemariya et al., 2017). They cannot grow in the presence of $6.5 \% \mathrm{NaCl}$ or at pH 9.6 (Buyukyoruk, 2007; Üstün et al., 2009). Their ability to ferment lactose is critically important, particularly in their use as starter cultures in the dairy industry. In addition to strains of lactococci of human origin, it is important to characterize the probiotic properties of strains isolated from raw milk, vegetables, and fermented milk products in the 
selection of starter culture strains. The consumption of food-origin lactococci at high levels, especially in raw milk and fermented milk products, is the basic criterion of their adaptation to the intestinal flora (Delgado et al., 2007; Parracho et al., 2007; Najera-Dominguez et al., 2014; Cavanagh et al., 2015). Lactococcus lactis ssp. lactis adapts easily to environments including milk or containing milk or dairy products and hence quickly and easily metabolizes lactose (Gutiérrez-Méndez et al., 2010). Probiotic bacteria include Lactobacillus and Bifidobacterium spp., and some yeasts, including Saccharomyces boulardii, have probiotic properties (Yadav et al., 2009).

Benefits of probiotic bacteria to human health include improving the gut microbiota balance and defending against pathogens. Other beneficial effects of probiotic microorganisms include stimulation of the immune system, reduction of blood cholesterol levels, synthesis of vitamins (particularly the vitamin B group), and anticarcinogenic and antimicrobial activities. Other criteria for a product to be regarded as a probiotic are consumer acceptance and survival of the probiotic microorganisms through the gastrointestinal tract. The recommended microorganism count in subjects consuming $100 \mathrm{~g} / \mathrm{d}$ of Lactobacillus acidophilus, Bifidobacterium animalis ssp. lactis, Lactobacillus casei, and other probiotic bacteria is 6 to $7 \mathrm{log} \mathrm{cfu} / \mathrm{g}$ or $\log$ $\mathrm{cfu} / \mathrm{mL}$ (Sarao and Arora, 2017). The health benefits of probiotic lactic acid bacteria vary depending on the strain, and these effects take place by different mechanisms.

There are various criteria for selecting the appropriate bacteria to be used as probiotics (Radulović et al., 2010; Soccoll et al., 2010; Giraffa, 2012). Lactococcus lactis can mostly be isolated from dairy products including raw milk and kefir grains. It is also used in starter cultures used for production of different dairy products including cheese. Based on its history of use in food fermentations, L. lactis has GRAS (generally regarded as safe) status. Lactococcus lactis produces lactic acid in dairy starter cultures and help to break down milk proteins during fermentation, contributing to the sensory and microbiological properties of the product (Cavanagh et al., 2015). In vitro and in vivo studies on the probiotic properties of L. lactis have suggested its use as a potential probiotic strain, in addition to improving the nutritional value of foods (Yadav et al., 2009; Lee et al., 2015). Raw milk maintains a suitable growing environment for Lactococcus species. Therefore, the aim of this study was to investigate and characterize the probiotic potential and biochemical and technological properties of L. lactis strains isolated from raw milk and kefir grains.

\section{MATERIALS AND METHODS}

\section{Materials}

Isolation and screening of LAB were conducted using 15 raw milk samples ( 7 cow and 8 goat) obtained from different regions of Izmir, Turkey, and 5 traditional kefir grain samples obtained from Department of Dairy Technology, Faculty of Agriculture, Ege University, Turkey.

\section{Methods}

Ten grams of each raw milk or kefir grain sample was weighed into a filtered stomacher bag and mixed with $90 \mathrm{~mL}$ of sterile $0.1 \%$ (wt/vol) peptone water (Merck, Darmstadt, Germany). All samples were serially diluted and $1 \mathrm{~mL}$ of each dilution was plated onto M17-lactose agar (Merck) containing nalidixic acid (Fluka, Steinheim, Switzerland). The M17 agar plates were incubated at $30^{\circ} \mathrm{C}$ under aerobic conditions for $48 \mathrm{~h}$. Following the incubation, appropriate colonies that have different morphologies (color, appearance, and shape) were transferred to Elliker broth (Difco, Fluka). Samples were incubated at $30^{\circ} \mathrm{C}$ for $48 \mathrm{~h}$ (Corroler et al., 1998; Buyukyoruk and Soyutemiz, 2010). A simple stain (methylene blue) was applied following morphological examination, and all gram-positive and catalase-negative $\left(\mathrm{H}_{2} \mathrm{O}_{2}, 2 \% \mathrm{vol} / \mathrm{vol}\right)$ isolates were purified and observed under a light microscope. The strains isolated from raw cow milk, raw goat milk, and kefir grains were coded as $\mathrm{K}$ (K1, K2, K3, K5, K7, K8, $\mathrm{K} 9$, and K10), Z (Z3, Z6, Z9, and Z10), and KR (KR4 and KR9), respectively. Isolates were screened for their ability to ferment 6 carbohydrates critical in L. lactis ssp. lactis identification (sorbitol, mannitol, arabinose, raffinose, xylose, and rhamnose). Lactococcus lactis ssp. lactis NRRL-B-1821 was used as the reference strain. All isolates were coded and stored in M17 broth containing equal amounts of $40 \%$ sterile glycerol at $-20^{\circ} \mathrm{C}$. After phenotypic identification, all bacteria were identified by PCR.

\section{DNA Isolation and Sequence Analysis}

Cultures were activated twice in Elliker broth and inoculated by swiping on M17-lactose agar. Bacterial DNA isolation, PCR, and sequencing analysis of the bacteria were carried out at REFGEN Gene Research and Biotechnology Laboratories (METU Technokent, Ankara, Turkey). Qiagen DNeasy Blood and Tissue DNA isolation kit (Qiagen, Hilden, Germany) was used for DNA isolation. For PCR, $50 \mu \mathrm{L}$ of $1 \times$ Taq buffer, 
$1.5 \mathrm{~m} M \mathrm{MgCl}, 0.2 \mathrm{~m} M$ deoxynucleotide triphosphates, $0.3 \mathrm{pmol} / \mu \mathrm{L}$ of each primer [27F (5'-AGAGTTTGATCATGGCTCAG-3') and 1492R (5'-GGTTACCTTGTTACGACTT- $3^{\prime}$ )], and $1.25 \mathrm{U}$ of Taq DNA polymerase (Thermo, Waltham, MA) were used. The PCR analysis was performed following these steps: pre-denaturation for 5 min at $94^{\circ} \mathrm{C} ; 30$ cycles of denaturation for $30 \mathrm{~s}$ at $94^{\circ} \mathrm{C}$; annealing for $30 \mathrm{~s}$ at suitable temperature for each primer pair; extension for $30 \mathrm{~s}$ at $72^{\circ} \mathrm{C}$; and final extension for $5 \mathrm{~min}$ at $72^{\circ} \mathrm{C}$. For DNA sequencing reactions, Applied Biosystems BigDye v3.1 Cycle Sequencing kit (Amersham Pharmacia Biotech Inc., Piscataway, NJ) was used. Following the sequencing reactions, samples were analyzed by using an ABI 3100 Genetic Analyzer (Applied Biosystems, Carlsbad, CA). The results were compared with the National Center for Biotechnology Information gene bank (http://www.ncbi.nlm.nih.gov) and aligned with ClustalW (https://www.genome.jp/ tools-bin/clustalw); the phylogenetic tree was drawn using the neighbor-joining method.

\section{Probiotic Properties of $L$. lactis ssp. lactis Strains}

Antimicrobial Activity. The optical densities (OD) of the active cultures were standardized by adjusting to $0.6 \pm 0.2$ at $600 \mathrm{~nm}$ using a spectrophotometer (Analytik Jena AG, Jena, Germany). To confirm that the antimicrobial activity was not related to acidity, cellfree culture supernatants at neutral $\mathrm{pH}$ were used, and the antimicrobial assays were prepared by growing the isolates in M17-lactose broth (Merck) at $30^{\circ} \mathrm{C}$ for $24 \mathrm{~h}$ and centrifuged at $6,654 \times g$ for $20 \mathrm{~min}$ at $4^{\circ} \mathrm{C}$. The antimicrobial activity of the cell-free culture supernatant was determined by disk diffusion assay according to the method of Tagg and McGiven (1971). This was followed by filtration of the supernatant through a $0.22-$ $\mu \mathrm{m}$ pore size filter (Merck) to obtain a cell-free filtrate. The antimicrobial activity of the isolated LAB (cell-free filtrate) against microorganisms such as Salmonella enterica ssp. enterica CECT 443, Salmonella choleraesuis ssp. choleraesuis ATCC 13076, Bacillus cereus CECT 131, Listeria monocytogenes CECT 932, Listeria monocytogenes ATCC 7644, Staphylococcus aureus ATCC 12600, Escherichia coli ATCC 25922, Escherichia coli CECT 4267, and Enterobacter aerogenes ATCC 13048 was assessed by disk diffusion assay (Warminska-Radyo et al., 2002). The pathogenic test bacteria were incubated in tryptic soy broth (Oxoid, Basingstoke, UK) at the appropriate temperature $\left(30-37^{\circ} \mathrm{C}\right)$ for $24 \mathrm{~h}$. Petri dishes containing $20 \mathrm{~mL}$ of tryptic soy agar (Oxoid) were prepared and inoculated with the incubated pathogenic bacteria. The microorganisms tested were adjusted according to McFarland 0.5 (10 $0^{8}$ microorgan- ism $/ \mathrm{mL}$ ) and a standard opacity was formed. Once the agar had solidified, the dishes were stored for $2 \mathrm{~h}$ in a refrigerator. Four wells were made and filled using 10 $\mu \mathrm{L}$ of the cell-free filtrate prepared previously. Petri dishes were incubated at $37^{\circ} \mathrm{C}$ for $24 \mathrm{~h}$. The inhibitory spectrum of the antimicrobial agent produced by the isolates of $L$. lactis strains against different indicator bacteria was determined by disk diffusion assay using Whatman 6-mm-diameter sterile disks (Rammelsberg and Radler, 1980).

Growth in the Presence of Bile Salt. The ability of $L$. lactis strains to grow in the presence of bile salt was determined according to Vinderola and Reinheimer (2003), with modifications. Strains were inoculated (1\% vol/vol) into Elliker broth (Difco, Fluka) and were incubated twice at $30^{\circ} \mathrm{C}$ for $24 \mathrm{~h}$, and cells were centrifuged and suspended. Then, M17 agar containing 0, $0.3,0.5,1$, or $2 \%$ (wt/vol) bile salt (Sigma Chemical Co., St. Louis, MO) was inoculated with $10 \mu \mathrm{L}$ of active culture. Results were evaluated as "growth" or "no growth."

Bile Salt Deconjugation. Bile salt deconjugation ability of L. lactis strains was determined according to the method of Taranto et al. (1995), with minor modifications. Elliker agars were prepared by adding $0.5 \%$ (wt/vol) sodium salts of taurocholic acid, taurodeoxycholic acid, glycocholic acid, and glycodeoxycholic acid (Sigma Chemical Co.). Elliker agar without bile salts was prepared as the control. The Petri dishes were inoculated with $10 \mu \mathrm{L}$ of active L. lactis culture and incubated aerobically at $30^{\circ} \mathrm{C}$ for $72 \mathrm{~h}$. The presence of precipitated bile acid around colonies (opaque halo) was considered a positive result.

Hydrophobicity. The ability of the L. lactis strains to adhere to hydrocarbons as a measure of their hydrophobicity was determined according to the method of Vinderola and Reinheimer (2003), with modifications. Cultures of the strains were harvested in stationary phase by centrifugation at $8,000 \times g$ for $10 \mathrm{~min}$ at $4^{\circ} \mathrm{C}$, washed twice in $50 \mathrm{mM} \mathrm{K}_{2} \mathrm{HPO}_{4}$ (pH 6.5) buffer, and resuspended in the same buffer. The cell suspension was adjusted to absorbance (at $560 \mathrm{~nm}, \mathrm{~A}_{560}$ ) of approximately 1.0 with buffer; then, $3 \mathrm{~mL}$ of the bacterial suspension was mixed with $0.6 \mathrm{~mL}$ of $n$-hexadecane and vortexed for $120 \mathrm{~s}$. The 2 phases were left to separate for $30 \mathrm{~min}$ at $37^{\circ} \mathrm{C}$. The aqueous phase was carefully removed and $\mathrm{A}_{560}$ was measured. The decrease in the absorbance of the aqueous phase was taken as a measure of the cell surface hydrophobicity $(\mathrm{H}, \%)$, which was calculated by using the formula; $\mathrm{H}(\%)=\left[\left(\mathrm{A}_{0}\right.\right.$ - A) $\left./ A_{0}\right] \times 100$, where $A_{0}$ and $A$ are the absorbance values before and after extraction with $n$-hexadecane, respectively. 
Biochemical and Technological Properties of $L$. lactis ssp. lactis Strains

Screening for Antibiotic Susceptibility. The disk diffusion method was used to screen the antibiotic susceptibility of isolates using 6-mm-diameter disks (Becton, Dickinson and Co., Franklin Lakes, NJ) containing 1 or 2 doses of ampicillin (10 and $25 \mu \mathrm{g}$ ), bacitracin $(10 \mu \mathrm{g})$, cefsulodin $(30 \mu \mathrm{g})$, chloramphenicol $(10 \mu \mathrm{g})$, clindamycin $(2$ and $10 \mu \mathrm{g})$, erythromycin $(10$ and $15 \mu \mathrm{g})$, gentamycin (10 and $120 \mu \mathrm{g}$ ), kanamycin $(30 \mu \mathrm{g})$, nalidixic acid $(30 \mu \mathrm{g})$, neomycin $(30 \mu \mathrm{g})$, novobiocin $(5 \mu \mathrm{g})$, oxacillin $(1$ and $5 \mu \mathrm{g})$, penicillin $(10 \mu \mathrm{g})$, polymyxin $\mathrm{B}(300 \mu \mathrm{g})$, streptomycin $(50$ and $300 \mu \mathrm{g})$, tetracycline $(30 \mu \mathrm{g})$, and vancomycin $(30 \mu \mathrm{g})$. Blank disks were used as the negative control. The tests were performed according to the criteria of the Clinical and Laboratory Standards Institute (CLSI) using Elliker agar. Inhibition-zone diameters were measured after aerobic incubation at $30^{\circ} \mathrm{C}$ for $24 \mathrm{~h}$. To facilitate the evaluation and interpretation of the results, the inhibition zones were evaluated as follows: 6 to $8 \mathrm{~mm}=-; 9$ to $14 \mathrm{~mm}=+, 15$ to $20 \mathrm{~mm}=++$, and 21 to $30 \mathrm{~mm}$ $=+++$ (Wikler, 2006; Shazali et al., 2014).

Decarboxylase Activity. The ability to produce biogenic amines by decarboxylation of AA was tested on a medium designed by Bover-Cid and Holzapfel (1999), which contained either of the precursor AA, Tyr or Lys. To induce decarboxylase activity before the screening test, the L. lactis strains were subcultured twice in M17 broth (Merck) containing $0.1 \%$ of each precursor AA and $0.005 \%$ pyridoxal-5-phosphate. The latter compound was previously shown to be important for inducing decarboxylase activity (Recsei et al., 1983). Ten-microliter volumes of each bacteria culture were then spotted onto agar plates with or without each AA and the plates were incubated aerobically at $37^{\circ} \mathrm{C}$ for 2 to $5 \mathrm{~d}$. Plates were observed for a purple color surrounding the formed colonies.

Lipolytic Activity. Lactococcus lactis strains were grown overnight at $30^{\circ} \mathrm{C}$ in M17 broth. Then, $10 \mu \mathrm{L}$ of fresh culture was placed on tributyrin agar containing $10 \mathrm{~mL} / \mathrm{L}$ neutral tributyrin (glycerol tributyrate; Merck; Leuschner et al., 1997). Plates were incubated at $30^{\circ} \mathrm{C}$ for $5 \mathrm{~d}$ and observed daily for halo formation around the colonies. The radius of the halo formation (in $\mathrm{mm}$ ) at the end of incubation was measured. For better monitoring of zone formation, $5 \%$ acetic acid solution was poured onto the Petri dishes, making the zones on the surface become more visible.

Antioxidant Activity. The antioxidant activity of L. lactis strains was estimated by 1,1-diphenyl-2-picrylhydrazyl (DPPH) assay (Sigma-Aldrich, St. Louis,
MO) according to Balakrishnan and Agrawal (2012), with modifications. Bacteria cultures were subcultured twice in M17 broth, transferred to reconstituted milk containing $12 \%$ nonfat DM at a $1 \%$ ratio, and incubated at $30^{\circ} \mathrm{C}$ for $24 \mathrm{~h}$. The samples were cooled to $4^{\circ} \mathrm{C}$ at the end of the incubation, and centrifuged at $6,654 \times g$ for $20 \mathrm{~min}$ at $4^{\circ} \mathrm{C}$. The separated supernatant was filtered through a sterile filter (Minisart, Sartorius, Göttingen, Germany) with 0.22- $\mu$ m-diameter pore size. One milliliter of $0.1 \mathrm{mM}$ DPPH (prepared in methanol) was mixed with $1.5 \mathrm{~mL}$ of methanol and $0.5 \mathrm{~mL}$ of supernatant and kept at $30^{\circ} \mathrm{C}$ for $30 \mathrm{~min}$; absorbance was measured at $517 \mathrm{~nm}$. Absorbance of the control sample was measured by mixing $1.5 \mathrm{~mL}$ of $\mathrm{DPPH}$ and $1.5 \mathrm{~mL}$ of methanol. Antioxidant activity of the bacteria was calculated using the following formula.

$$
\text { Antioxidant activity }(\%)=\mathrm{A}-[(\mathrm{B}-\mathrm{C}) \times 100 / \mathrm{A}] \text {, }
$$

where $\mathrm{A}=$ absorbance of DPPH solution with no sample; $\mathrm{B}=$ absorbance of sample + DPPH solution; and $\mathrm{C}=$ absorbance of blank, which did not contain DPPH.

\section{RESULTS AND DISCUSSION}

Based on the phenotypic and sequence analyses, the 14 strains with the best morphological and growth properties were L. lactis ssp. lactis, and the biochemical and probiotic properties of those strains were analyzed. Lactococcus lactis ssp. cremoris and L. lactis ssp. lactis are mostly found in dairy products, including raw milk, soft and hard cheeses, and sour cream (Ward et al., 2002; Casalta and Montel, 2008). However, some studies have reported that Lactococcus species are found not only in milk and dairy products but can be isolated from other sources, such as German sauerkraut (Harris et al., 1992), fermented sausages (Noonpakdee et al., 2003), river water (Zendo et al., 2003), and human milk (Beasley, 2004).

\section{Probiotic Properties of L. lactis ssp. lactis Strains}

Antimicrobial Activity. Inhibitory effects of LAB are due to the natural protective organic acids, hydrogen peroxide, diacetyl, bacteriocins, and specific substances, such as antiviral peptides or low-molecularweight peptides (reuterin, reutericyclin; Fan and Song, 2013; Viana de Souza and Silva Dias, 2017). The LAB inhibit the development of pathogenic microorganisms and food-degrading microorganisms by competing for food with pathogens that shorten the shelf life of food products. The most commonly known bacteriocins produced by lactococci are nisin, lactococcin A, lactococ- 
cin B, lactococcin MN, lactococcin G, lactococcin 972, lacticin 481, lacticin 3147, lacticin FS92, lacticin RM, lacticin NK24, lactococcin R, lactococcin MMT24, and lactococcin MMFII, (Davidson and Hoover, 1993; Rattanachaikunsopon and Phumkhachorn, 2010; Šušković et al., 2010). Table 1 shows that none of the Lactococcus lactis strains studied here showed antimicrobial activity against Bacillus cereus CECT131. Lactococcus lactis K5 had an effect only on Enterobacter aerogenes ATCC 13048, whereas K9 had an effect only on Listeria monocytogenes ATCC 7644. However, K9 had no effect on Listeria monocytogenes CECT 932. Similarly, a lower level of inhibitory activity was observed against Escherichia coli CECT 4267, whereas activity against Escherichia coli ATCC 25922 was higher. Strains Z9 and Z3 were not effective against Bacillus cereus CECT 131 but had the highest antimicrobial activity against other pathogens. Additionally, the lowest antimicrobial activity was observed against Salmonella choleraesuis ssp. choleraesuis ATCC 13076 and Escherichia coli CECT 4267 bacteria. Only 4 of the L. lactis strains (Z3, Z6, Z9, and Z10) were effective against these 2 indicator bacteria. In generally, most of the L. lactis strains isolated and identified in the study were effective against Enterobacter aerogenes ATCC 13048; only strain K10 had no effect on this pathogen. The bestdefined bacteriocin is nisin, which can be produced by

Growth in Bile Salts at Different Concentrations. The physiological concentration of bile salts in the intestinal tract varies between 0.3 and $0.5 \%$ (Begley et al., 2005). The resistance to bile salts property of probiotic microorganisms is associated with activity of bile salt hydrolase, which reduces the inhibitory effect of bile by hydrolyzing conjugated bile salts (Oh et al., 2000; Mourad and Nour-Eddine, 2006). The growth of $L$. lactis strains in the presence of various concentrations of bile salts is shown in Table 2. None of the strains were able to grow in the presence of $0.3,0.50$, 1 , or $2 \%$ bile salt. In contrast to the results obtained in the current study, Vinderola and Reinheimer (2003) reported that the viability of 9 strains of L. lactis in the presence of $0.3 \%$ bile salt varied between 21.3 and $76.6 \%$. Vinderola and Reinheimer (2003) found that probiotic bacteria are more resistant to bile salt than are LAB; specifically, most Streptococcus thermophilus species are susceptible to $0.5 \%$ bile salt. Additionally, previous research (Kim et al., 1999; Kimoto-Nira et al., 2009; Kaya Ozdogan et al., 2012) reported that L. lactis was resistant even to $1 \%$ bile salt, whereas Ertekin and Çon (2014) showed that 2 different L. lactis strains could grow even in the presence of $9 \%$ bile salt. Klijn et al. (1995) reported that Lactobacillus delbrueckii ssp. bulgaricus and Lactococcus spp. were resistant to bile some strains of L. lactis.

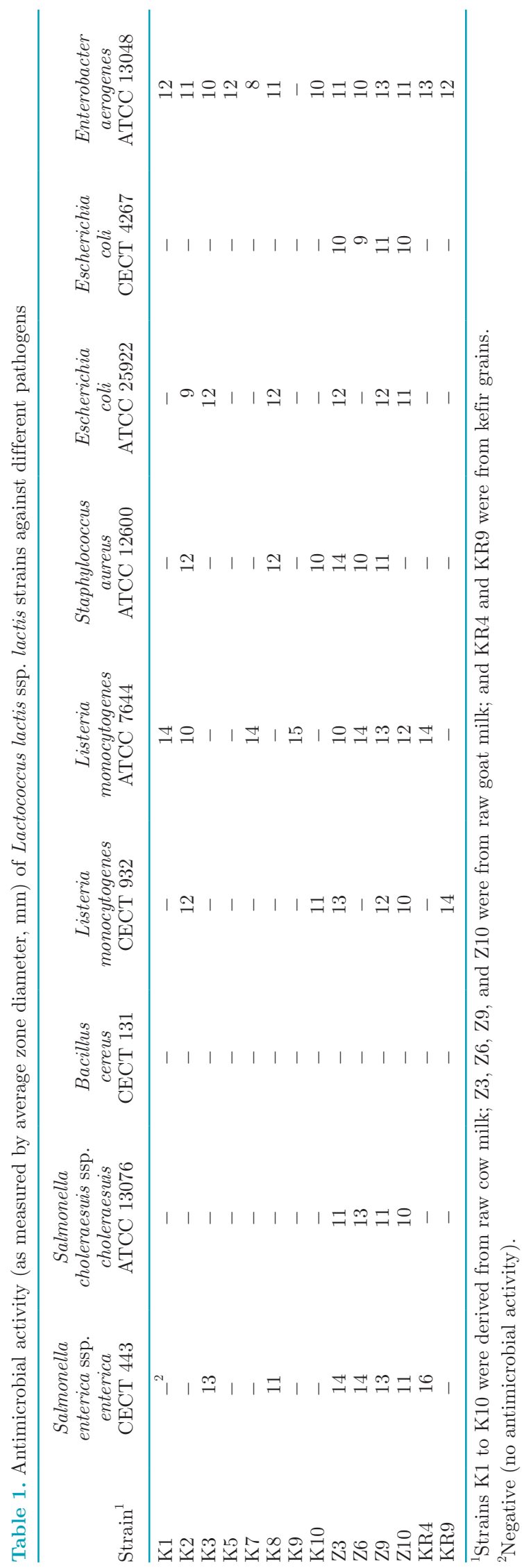

Journal of Dairy Science Vol. 102 No. 1, 2019 
Table 2. Probiotic properties of Lactococcus lactis ssp. lactis strains

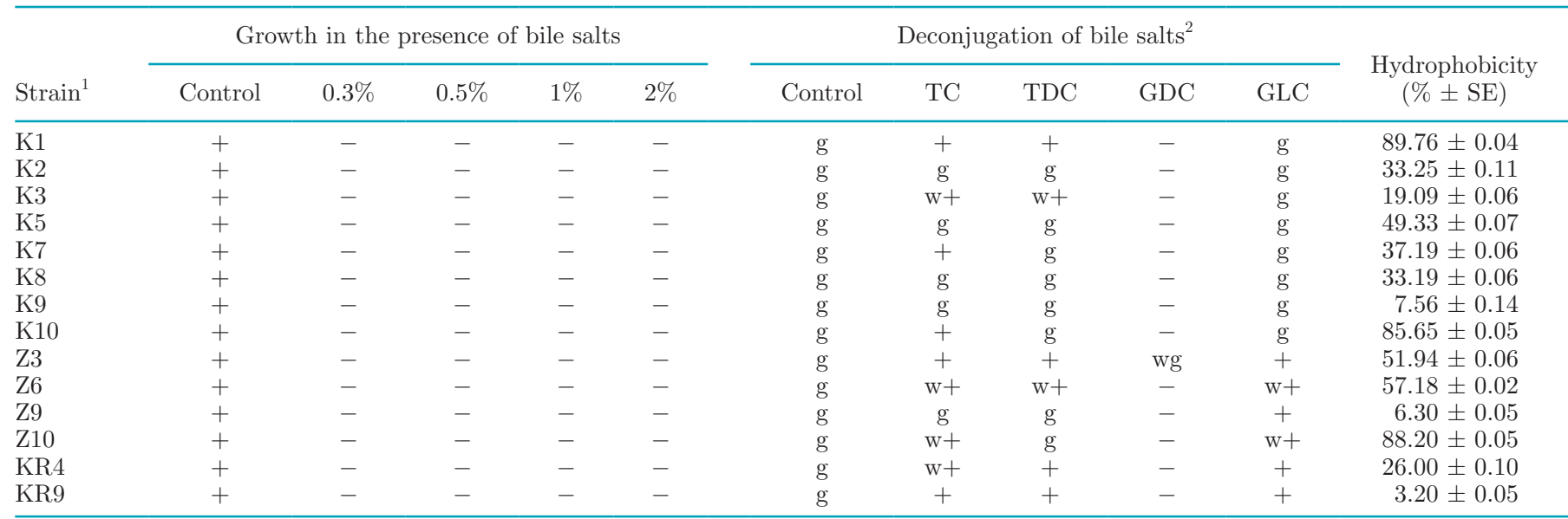

${ }^{1}$ Strains K1 to K10 were derived from raw cow milk; Z3, Z6, Z9, and Z10 were from raw goat milk; and KR4 and KR9 were from kefir grains.

${ }^{2} \mathrm{TC}=$ taurocholic acid, TDC $=$ taurodeoxycholic acid, GDC $=$ glycodeoxycholic acid; GLC = glycocholic acid; $-=$ negative, no growth; $+=$ positive, growth and deconjugation of the bile salts; $\mathrm{w}+=$ weak positive, $\mathrm{wg}=$ weak growth, $\mathrm{g}=$ growth.

salts. Todorova et al. (2007) reported that L. lactis strains isolated from human vaginal secretions could grow in the presence of $0.3 \%$ bile salt. Lactococcus lactis strains isolated from raw milk and kefir grains cannot grow in the presence of bile salt and this is regarded as a negative characteristic regarding probiotic properties. However, the results regarding the ability to grow in bile salt were ignored in this study because even though the lack of growth in bile salts is an unfavorable property of a probiotic, the use of these strains as functional cultures cannot be overlooked because of the positive characteristics of the strains, including bile salt deconjugation.

Bile Salt Deconjugation Properties. Bile salt deconjugation has an important role in regulating the gut microflora and reducing serum cholesterol levels. Accordingly, the presence of this activity is significant when selecting species that will be used as fortification or adjunct cultures (Corzo and Gilliland, 1999; Vinderola and Reinheimer, 2003). Bile salt deconjugation abilities of L. lactis on 4 bile salts are given in Table 2 . Five of the L. lactis strains (K1, K7, Z3, Z6, and KR9) deconjugated taurocholic acid, 4 strains had weak (K3, Z6, Z10, and KR4) deconjugation effects, whereas 5 strains (K2, K5, K8, K9, and Z9) had no deconjugation activity, but showed growth in the presence of bile salts. Four strains fully deconjugated taurodeoxycholic acid, 2 of the strains had a weak deconjugation activity, and 8 of the strains were not able to grow in the presence of that bile salt. None of the strains were able to deconjugate or grow in the presence of glycodeoxycholic acid, and only 1 strain presented weak growth activity.
Four strains showed deconjugation activity in the presence of glycodeoxycholic bile salt, and weak deconjugation activity detected in 2 strains. Eight strains were able to grow in this bile salt. Vinderola and Reinheimer (2003) reported that LAB do not present deconjugation properties; however, Lactobacillus bulgaricus and Streptococcus thermophilus strains were affected by bile salts (taurocholic acid, taurodeoxycholic acid, glycocholic acid, and glycodeoxycholic acid). Thus, L. lactis strains were not able to grow in the presence of bile salts at concentrations of 0.3 to $2 \%$, but they were able to grow or deconjugate bile salts such as taurocholic acid, taurodeoxycholic acid, and glycodeoxycholic acid.

Hydrophobicity. Bacterial adhesion was determined to assess the adherence potential of microorganisms to surface hydrocarbons, which is a measure of adhesion to epithelial cells of the gut (Yadav et al., 2016). Table 2 shows the hydrophobicity of L. lactis strains. Hydrophobicity values varied between 3.20 and $89.76 \%$; the highest hydrophobicity was determined in strain K1. Hydrophobic potential is organism- and strain-specific and can be affected by the age and surface chemistry of strains as well as by the composition of the culture medium (Puniya et al., 2016). Vinderola and Reinheimer (2003) found hydrophobicity values of 9 L. lactis strains to range between 14.9 and $31.3 \%$. Hydrophobicity can be advantageous for strains that are in competition with other bacteria in the gastrointestinal system (Naidu et al., 1999; Todorova et al., 2007). Ouwehand et al. (1999) reported a correlation between surface hydrophobicity and adhesion abilities of bacteria. KayaOzdogan (2011) reported that the optical density of a 
cell suspension of L. lactis strain isolated from Turkey was between 0.93 and 1.09 before treatment with $n$ hexadecane and between 0.15 and 0.18 after treatment, whereas hydrophobicity was $83.48 \pm 1.45 \%$. Although there is no standard value of hydrophobicity sought in bacteria, high hydrophobicity is a positive feature in terms of probiotic properties.

\section{Biochemical and Technological Properties of L. lactis Strains}

Antibiotic Susceptibility. Antibiotic susceptibility and resistance of L. lactis strains to various antibiotics in different concentrations are given in Table 3. All $L$. lactis strains in the study were resistant to $30 \mu \mathrm{g}$ of nalidixic acid and were able to grow in this concentration. Only L. lactis Z6 showed resistance to clindamycin at $2 \mu \mathrm{g}$, whereas all strains were susceptible to $10 \mu \mathrm{g}$ of clindamycin; 1 strain (Z6) was susceptible to $30 \mu \mathrm{g}$ and 4 strains (Z3, Z6, Z10, and KR4) were susceptible to $10 \mu \mathrm{g}$ of tetracycline; 2 strains (Z3 and Z6) were susceptible to $10 \mu \mathrm{g}$ of bacitracin; and 2 strains (Z10 and KR4) were susceptible to $30 \mu \mathrm{g}$ of neomycin. All L. lactis strains were susceptible to $30 \mu \mathrm{g}$ of vancomycin, to 10 and $25 \mu \mathrm{g}$ of ampicillin, and to $10 \mathrm{IU}$ of penicillin, and the diameters of the susceptibility zones that formed increased as the antibiotic concentrations increased. Three strains (Z3, Z10, and KR9) were susceptible to $300 \mathrm{U}$ of polymyxin $\mathrm{B}$, whereas 1 strain (Z6) was resistant to $30 \mu \mathrm{g}$ of cefsulodin. All L. lactis strains were susceptible to erythromycin; the higher concentration affected the resistance that some strains have shown. Twelve strains were resistant to $10 \mu \mathrm{g}$ but only 2 strains (Z9 and KR9) were resistant to $120 \mu \mathrm{g}$ of gentamicin. Similarly, 2 strains (Z6 and KR9) were resistant to $50 \mu \mathrm{g}$ of streptomycin and none were resistant to $300 \mu \mathrm{g}$. It was found that most strains were susceptible to $10 \mu \mathrm{g}$ of chloramphenicol and, of the 14 strains, only 2 (Z3 and Z6) were resistant. In contrast, most strains (9 strains) were resistant to 30 $\mu \mathrm{g}$ of kanamycin. Five strains (K1, K2, K3, Z3, and Z6) were resistant to $1 \mu \mathrm{g}$ of oxacillin, whereas only 1 strain (Z6) was resistant to $5 \mu \mathrm{g}$. Kaya-Ozdogan (2011) reported that the nisin A-producing L. lactis LL27 strain originating in Turkey was susceptible to penicillin G, ampicillin, cefazolin, meropenem, imipenem, vancomycin, amoxicillin-clavulanic acid, ceftiofur, amikacin, gentamicin, kanamycin, spectinomycin, tetracycline, chloramphenicol, erythromycin, azithromycin, florfenicol, ciprofloxacin, lincomycin, and ofloxacin, but was resistant to streptomycin, polymyxin $\mathrm{B}$, and neomycin. In general, L. lactis strains are susceptible to broadspectrum antibiotics and $\beta$-lactam antibiotics, which are effective against gram-positive bacteria; however,

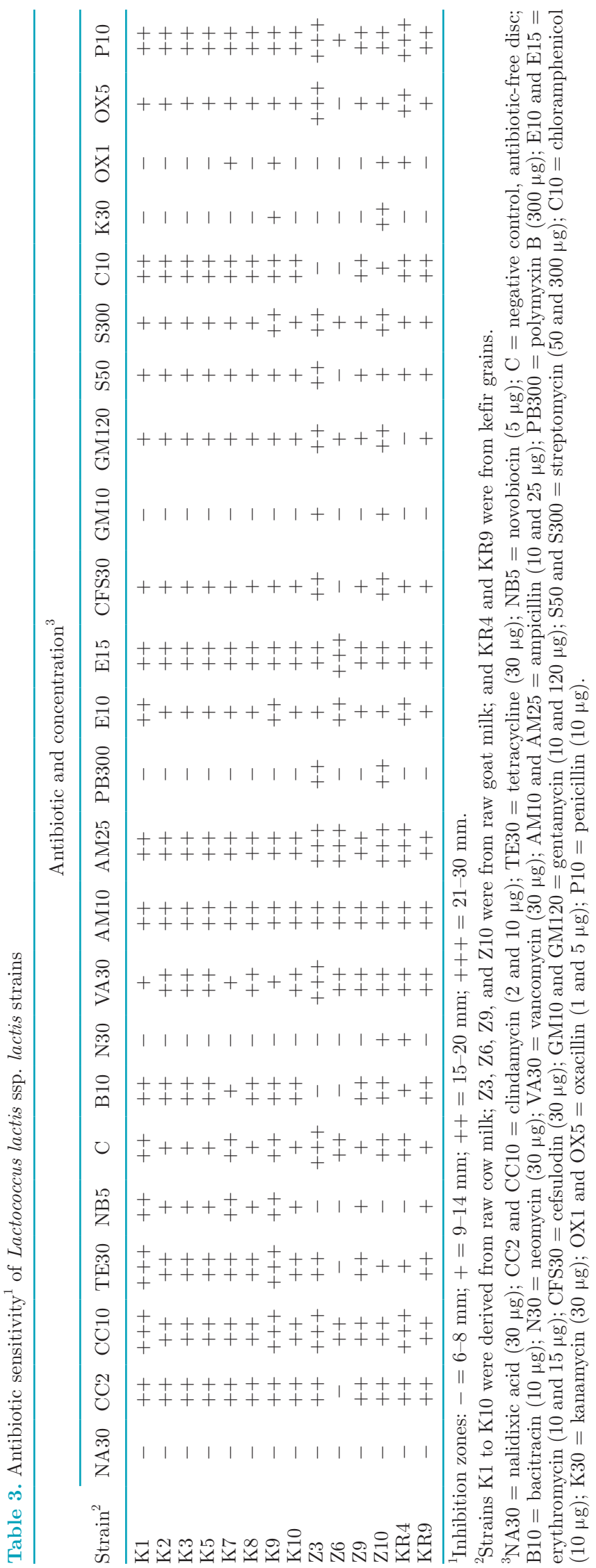


L. lactis strains are resistant to cefoxitin, amygdalin, gentamycin, and kanamycin, antibiotics are effective against gram-negative bacteria. As we observed, the susceptibility to tetracycline, cephalothin, nitrofurantoin, and cefotetan varies from strain to strain. As in lactobacilli, some rare L. lactis strains are resistant to chloramphenicol, clindamycin, streptomycin, erythromycin, and tetracycline (Flórez et al., 2005; Ammor et al., 2007; Khemariya et al., 2017). Sahnouni et al. (2012) reported that L. lactis MT and ST2 strains were susceptible to penicillin, chloramphenicol, tetracycline, amikacin, and erythromycin, and resistant to vancomycin and nalidixic acid.

Decarboxylation Activity. To prevent the formation of biogenic amines in commercial food products, it is important to fortify these products with starter cultures that do not have AA decarboxylase activity. Biogenic amines are agents that can be formed during the production, processing, and storage of fermented protein-rich foods, and excessive intake of biogenic amines via foods can result in toxic effects (Naila et al., 2010; Spano et al., 2010; Linares et al., 2011). Table 4 shows the decarboxylation activity of $L$. lactis strains on lysine and tyrosine. None of the strains decarboxylated either Lys or Tyr. In contrast, Sahnouni et al. (2012) found that L. lactis MT and ST2 strains produced biogenic amines from lysine, ornithine, histidine, and tyrosine. All strains of L. lactis isolated from raw milks and kefir grains tested in the current study failed to decarboxylate lysine and tyrosine, and this is regarded as a positive characteristic. As with many other characteristics, decarboxylation activity of L. lactis strains varies depending on the strain.

Lipolytic Activity. Lipolysis is the process whereby lipids are hydrolyzed to glycerin and fatty acids by the effects of lipolytic enzymes such as lipase. The lipase activity of LAB varies depending on genus and species, and many LAB show limited and weak lipase activity. Although lipolytic activity in products such as milk, yogurt, and butter is not highly desired, a certain level of lipolysis is desirable in some types of cheese in terms of formation of aroma and structure. None of the L. lactis ssp. lactis strains in the study had lipolytic activity (Table 4). Katz et al. (2002), in their study on lipolytic activity of LAB, found that L. lactis O233 strain was not able to hydrolyze triglycerides including tributyrin. Sahnouni et al. (2012) reported that L. lactis strains isolated from the gastrointestinal tract of coastal fish had no lipolytic activity. Researchers have noted that some bacterial strains had no lipolytic activity in tributyrin agar containing glycerol tributyrate, although these strains could hydrolyze milk fat and form free fatty acids (Martínez-Moreno, 1976; Serio et al., 2010). Therefore, strains that had no lipolytic activity in agar did show have lipolytic activity in dairy products.

Antioxidant Activity. Several studies have reported antioxidant activities in lactobacilli using milk casein as substrate. Several methods can be used to evaluate the antioxidant activity of the protein hydrolysate; for example, DPPH, ferrous ion chelating activity, reducing power, 2,2-azino-bis-3-ethylbenzthiazoline-6-sulfonic acid radical scavenging activity, and linoleic acid and

Table 4. Decarboxylation of AA, lipolytic activity, and antioxidant activity properties of Lactococcus lactis ssp. lactis strains

\begin{tabular}{|c|c|c|c|c|}
\hline \multirow[b]{2}{*}{ Strain $^{1}$} & \multicolumn{2}{|c|}{ Decarboxylation of AA } & \multirow{2}{*}{$\begin{array}{l}\text { Lipolytic } \\
\text { activity }\end{array}$} & \multirow{2}{*}{$\begin{array}{l}\text { Antioxidant activity } \\
(\mathrm{DPPH} \% \pm \mathrm{SE})^{2}\end{array}$} \\
\hline & Lysine & Tyrosine & & \\
\hline$\overline{\mathrm{K} 1}$ & $-{ }^{3}$ & - & - & $29.67 \pm 0.03$ \\
\hline K2 & - & - & - & $32.26 \pm 0.04$ \\
\hline K3 & - & - & - & $23.10 \pm 0.05$ \\
\hline K5 & - & - & - & $24.95 \pm 0.05$ \\
\hline $\mathrm{K} 7$ & - & - & - & $33.74 \pm 0.06$ \\
\hline K8 & - & - & - & $25.97 \pm 0.03$ \\
\hline K9 & - & - & - & $16.34 \pm 0.06$ \\
\hline K10 & - & - & - & $16.07 \pm 0.03$ \\
\hline $\mathrm{Z} 3$ & - & - & - & $32.72 \pm 0.03$ \\
\hline $\mathrm{Z} 6$ & - & - & - & $24.39 \pm 0.01$ \\
\hline Z9 & - & - & - & $20.97 \pm 0.03$ \\
\hline $\mathrm{Z} 10$ & - & - & - & $22.08 \pm 0.02$ \\
\hline KR4 & - & - & - & $10.35 \pm 0.05$ \\
\hline KR9 & - & - & - & $17.27 \pm 0.03$ \\
\hline
\end{tabular}

${ }^{1}$ Strains K1 to K10 were derived from raw cow milk; Z3, Z6, Z9, and Z10 were from raw goat milk; and KR4 and KR9 were from kefir grains.

${ }^{2} \mathrm{DPPH}=1,1$-diphenyl-2-picrylhydrazyl assay.

${ }^{3}$ Where $-=$ negative, measured as the purple color surrounding the formed colonies (presence of Tyr or Lys). 
superoxide anion radical-scavenging activity assay. The DPPH assay has been widely used in the determination of antioxidant activities of cell free extracts of bacteria; DPPH is a relatively stable organic radical. The DPPH assay is based on the reduction of DPPH in methanol, in the presence of a hydrogen-donating antioxidant, to the nonradical form, DPPH-H (Paulpriya and Mohan 2012). The antioxidant activity of L. lactis strains in terms of DPPH scavenging capacity are given in Table 4. Antioxidant activity varied depending on the strain and varied between 10.35 and $33.74 \%$. The highest antioxidant activity was determined in strain $\mathrm{K} 7$ and the lowest in KR4. Kaya-Ozdogan (2011) reported that the DPPH scavenging capacity of the nisin A-producing L. lactis LL27 strain was $75 \pm 3 \%$. The antioxidant capacities obtained in this study were lower than those reported in Kaya-Ozdogan (2011), indicating that the antioxidant activity of L. lactis can vary by source and strain.

\section{CONCLUSIONS}

In this study, the probiotic potential and biochemical and technological properties of L. lactis ssp. lactis strains isolated from raw milk and kefir grains were examined in terms of antimicrobial activity, growth in the presence of bile salts, bile salts deconjugation, hydrophobicity, antibiotic susceptibility, and lipolytic, decarboxylation and antioxidant activities. The inability of strains to grow in the presence of $0.3 \%$ bile salt is regarded as a negative characteristic for a potential probiotic, but this does not mean that such strains do not demonstrate viability. They can be used as functional starter cultures due to their antimicrobial activities, high hydrophobicity, antioxidant activities, and ability to deconjugate bile salts. Lactococcus lactis strains isolated from kefir grains had better probiotic properties than those from raw milk, whereas strains from raw milk presented better biochemical and technological properties. The strains that exhibited appropriate biochemical properties, antimicrobial activity in particular, can be used as functional cultures, but they cannot be regarded as probiotic because they were not resistant to bile salts. Thus, L. lactis did not exhibit probiotic properties because it did not show required characteristics. It would be better to use L. lactis strains with appropriate biochemical properties by combining them with other functional cultures rather than using them as a single culture.

\section{ACKNOWLEDGMENTS}

The author declares no conflict of interest.

\section{REFERENCES}

Ammor, M. S., A. B. Florez, and M. Baltasar. 2007. Antibiotic resistance in nonenterococcal lactic acid bacteria and bifidobacteria. Food Microbiol. 24:559-570.

Axelsson, L., and S. Ahrné. S. 2000. Lactic acid bacteria. Pages 365386 in Applied Microbial Systematics. F. G. Priest, and M. Goodfellow, ed. Kluwer Academic, Dordrecht, the Netherlands.

Balakrishnan, G., and R. Agrawal. 2012. Antioxidant activity and fatty acid profile of fermented milk prepared by Pediococcus pentosaceus. J. Food Sci. Technol. 51:4138-4142.

Balciunas, E. M., F. A. Castillo Martinez, S. D. Todorov, B. D. G. D. M. Franco, A. Converti, and R. P. D. S. Oliveira. 2013. Novel biotechnological applications of bacteriocins: A review. Food Control $32: 134-142$.

Beasley, S. 2004. Isolation, identification and exploitation of lactic acid bacteria from human and animal microbiota. PhD Thesis. Department of Applied Chemistry and Microbiology, Faculty of Agriculture and Forestry and Viikki, Graduate School in Biosciences, Helsinki, Finland.

Begley, M., C. G. Gahan, and C. Hill. 2005. The interaction between bacteria and bile. FEMS Microbiol. Rev. 29:625-651.

Bover-Cid, S., and W. H. Holzapfel. 1999. Improve screening procedure for biogenic amine production by lactic acid bacteria. Int. J. Food Microbiol. 53:33-41.

Buyukyoruk, S. 2007. Isolation of Lactococcus lactis ssp. lactis and Lactococcus lactis ssp. cremoris strains from traditionally manufactured Izmir Tulum cheese and biochemical and PCR identification. PhD Thesis. Uludag University, Bursa, Turkey. (in Turkish)

Buyukyoruk, S., and G. E. Soyutemiz. 2010. Isolation of Lactococcus lactis (Lactococcus lactis subspecies lactis vs. subspecies cremoris) strains from traditionally manufactured İzmir Tulum cheese and identification by phenotypical and molecular technics. J. Vet. Med. Erciyes Univ. 7:81-87. (in Turkish).

Casalta, E., and M. C. Montel. 2008. Safety assessment of dairy microorganisms: The Lactococcus genus. Int. J. Food Microbiol. 126:271-273.

Cavanagh, D., G. F. Fitzgerald, and O. McAuliffe. 2015. From field to fermentation: The origins of Lactococcus lactis and its domestication to the dairy environment. Food Microbiol. 47:45-61.

Corroler, D., I. Manguin, N. Desmasures, and M. Gueguen. 1998. An ecological study of lactococci isolated from raw milk in the camembert cheese registered designation of origin area. Appl. Environ. Microbiol. 64:4729-4735.

Corzo, G., and S. E. Gilliland. 1999. Bile salt hydrolase activity of three strains of Lactobacillus acidophilus. J. Dairy Sci. 82:472-480.

Davidson, M. P., and D. G. Hoover. 1993. Lactic Acid Bacteria. S. Salminen, and A. von Wright, ed. Marcel Dekker Inc., New York, NY.

Delgado, S., E. O'Sullivan, G. Fitzgerald, and B. Mayo. 2007. Subtractive screening for probiotic properties of Lactobacillus species from the human gastrointestinal tract in the search for new probiotics. J. Food Sci. 72:M310-315.

Ertekin, Ö., and A. H. Çon. 2014. Industrial and probiotic characteristics of lactic acid bacteria isolated from fermented foods. Acad. Food J. 12:6-16. (In Turkish).

Fan, L., and J. Song. 2013. Antimicrobial microbes-bacteriocin producing lactic acid bacteria. Pages 899-909 in Microbial Pathogens and Strategies for Combating Them: Science, Technology and Education. A. Méndez-Vilas, ed. Formatex Research Center, Badajoz, Spain.

Flórez, A. B., S. Delgado, and B. Mayo. 2005. Antimicrobial susceptibility of lactic acid bacteria isolated from a cheese environment. Can. J. Microbiol. 51:51-58.

Furet, J. P., P. Quenee, and P. Tailliez. 2004. Molecular quantification of lactic acid bacteria in fermented milk products using real-time quantitative PCR. Int. J. Food Microbiol. 97:197-207.

Giraffa, G. 2012. Selection and design of lactic acid bacteria probiotic cultures. Eng. Life Sci. 12:391-398.

Gutiérrez-Méndez, N., J. C. Rodríguez-Figueroa, A. F. González-Cordova, G. V. Nevárez-Moorillón, B. Rivera-Chavira, and B. Vallejo- 
Cordoba. 2010. Phenotypic and genotypic characteristics of Lactococcus lactis strains isolated from different ecosystems. Can. J. Microbiol. 56:432-439.

Harris, L. J., H. P. Flemming, and T. R. Klaenhammer. 1992. Characterization of two nisin-producing Lactococcus lactis ssp. lactis strains isolated from a commercial sauerkraut fermentation. Appl. Environ. Microbiol. 58:1477-1483.

Katz, M., R. Medina, S. González, and G. Oliver. 2002. Esterolytic and lipolytic activities of lactic acid bacteria isolated from ewe's milk and cheese. J. Food Prot. 65:1997-2001.

Kaya-Ozdogan, D. 2011. Probiotic properties of Lactococcus lactis ssp. lactis LL27. MS Thesis. Department of Biology, Ankara University Graduate School of Natural and Applied Sciences, Ankara, Turkey. (in Turkish)

Kaya Ozdgan, D., N. Akcelik, B. Aslim, Z. Suludere, and M. Akcelik. 2012. Probiotic and antioxidative properties of L. lactis LL27 isolated from milk. Biotechnol. Biotec. Eq. 26:2750-2758.

Khemariya, P., S. Singh, G. Nath, and A. K. Gulati. 2017. Probiotic Lactococcus lactis: A review. Turk. J. Agric. Food Sci. Tech. 5:556-562.

Kim, W. S., J. Ren, and N. W. Dunn. 1999. Differentiation of Lactococcus lactis subspecies lactis and subspecies cremoris strains by their adaptive response to stresses. FEMS Microbiol. Lett. 171:57-65.

Kimoto-Nira, H., M. Kobayashi, M. Nomura, K. Sasaki, and C. Suzuki. 2009. Bile resistance in Lactococcus lactis strains varies with cellular fatty acid composition: Analysis by using different growth media. Int. J. Food Microbiol. 131:183-188.

Klijn, N., A. H. Weerkamp, and W. M. Vos. 1995. Detection and characterization of lactose-utilizing Lactococcus spp. in natural ecosystems. Appl. Environ. Microbiol. 61:788-792.

Kojic, M., I. Strahinic, D. Fira, B. Jovcic, and L. Topisirovic. 2006. Plasmid content and bacteriocin production by five strains of $\mathrm{Lac}$ tococcus lactis isolated from semi-hard homemade cheese. Can. J. Microbiol. 52:1110-1120.

Lee, N.-K., K. J. Han, S.-H. Son, S. J. Eom, S.-K. Lee, and H.-D. Paik. 2015. Multifunctional effect of probiotic Lactococcus lactis KC24 isolated from kimchi. Food Sci. Tech. (Paris) 64:1036-1041.

Leuschner, R. G., P. M. Keneally, and E. K. Arendt. 1997. Methods for the rapid quantitative detection of lipolytic activity among food fermenting microorganisms. Int. J. Food Microbiol. 37:237-240.

Linares, D. M., M. C. Martín, V. Ladero, M. A. Alvarez, and M. Fernández. 2011. Biogenic amines in dairy products. Crit. Rev. Food Sci. Nutr. 51:691-703.

Martínez-Moreno, J. L. 1976. Microbial flora of Manchego cheese: III. Streptococci. Anales del INIA Serie General 4:41-56.

Mourad, K., and K. Nour-Eddine. 2006. Microbiological study of naturally fermented Algerian green olives: Isolation and identification of lactic acid bacteria and yeasts along with the effects of brine solutions obtained at the end of olive fermentation on Lactobacillus plantarum. Grasas Aceites 57:292-300.

Naidu, A. S., W. R. Bidlack, and R. A. Clemens. 1999. Probiotic spectra of lactic acid bacteria (LAB). Crit. Rev. Food Sci. Nutr. 39:13-126.

Naila, A., S. Flint, G. Fletcher, P. Bremer, and G. Meerdink. 2010 Control of biogenic amines in food-Existing and emerging approaches. J. Food Sci. 75:R139-R150.

Najera-Dominguez, C., N. Gutierrez-Mendez, K. Aguirre-Gardea, A. Peralta-Bolivar, D. R. Chavez-Garay, and M. Y. Leal-Ramos 2014. Texture properties of miniature Chihuahua-type cheese manufactured with different strains of Lactococcus lactis isolated from plants and raw milk cheese. J. Texture Stud. 45:487-494.

Noonpakdee, W., C. Santivarangkna, P. Jumriangrit, K. Sonomoto, and S. Panyim. 2003. Isolation of nisin-producing Lactococcus lactis WNC 20 strain from nham, a traditional Thai fermented sausage. Int. J. Food Microbiol. 81:137-145.

Oh, S., S. H. Kim, and R. W. Worobo. 2000. Characterization and purification of a bacteriocin produced by a potential probiotic culture, Lactobacillus acidophilus 30SC. J. Dairy Sci. 83:2747-2752.
Ouwehand, A. C., P. V. Kirjavainen, M. M. Grünland, E. Isolavri, and S. J. Salminen. 1999. Adhesion of probiotic microorganisms to intestinal mucus. Int. Dairy J. 9:623-630.

Parracho, H., A. L. McCartney, and G. R. Gibson. 2007. Probiotics and prebiotics in infant nutrition. Proc. Nutr. Soc. 66:405-411.

Paulpriya, K., and V. R. Mohan. 2012. In vitro antioxidant potential of methanol extract of Dioscorea oppositifolia. Sci. Res. Rep. 2:239-245.

Puniya, M., M. R. Kumar, H. Panwar, N. Kumar, Ramneek, and A. Kumar. 2016. Screening of lactic acid bacteria of different origin for their probiotic potential. J. Food Process. Technol. 7:545.

Radulović, Z., T. Petrović, V. Nedović, S. Dimitrijević, N. Mirković, M. Petrušić, and D. Paunović. 2010. Characterization of autochthonous Lactobacillus paracasei strains on potential probiotic ability. Mljekarstvo 60:86-93.

Rammelsberg, M., and F. Radler. 1980. Antibacterial polypeptides of Lactobacillus species. J. Appl. Bacteriol. 69:177-184.

Rattanachaikunsopon, P., and P. Phumkhachorn. 2010. Lactic acid bacteria: Their antimicrobial compounds and their uses in food production. Ann. Biol. Res. 1:218-228.

Recsei, P. A., W. M. Moore, and E. E. Snell. 1983. Pyruvolyl-dependent histidine decarboxylases from Clostridium perfringens and Lactobacillus buchneri. J. Biol. Chem. 258:439-444.

Sahnouni, F., A. Matallah-Boutiba, D. Chemlal, and Z. Boutiba. 2012 Technological characterization of lactic acid bacteria isolated from intestinal microbiota of marine fish in the Oran Algeria coast. Afr. J. Microbiol. Res. 6:3125-3133.

Salminen, S., M. Deighton, and S. Gorbach. 1993. Lactic acid bacteria in health and disease. Pages 199-225 in Lactic Acid Bacteria. Marcel Dekker, New York, NY.

Sarao, L. K., and M. Arora. 2017. Probiotics, prebiotics, and microencapsulation: A review. Crit. Rev. Food Sci. Nutr. 57:344-371.

Schlegel, H. G. 1997. General Microbiology. Cambridge University Press, New York, NY.

Serio, A., C. Chaves-López, A. Paparella, and G. Suzzi. 2010. Evaluation of metabolic activities of enterococci isolated from Pecorino Abruzzese cheese. Int. Dairy J. 20:459-464.

Shazali, N., H. L. Foo, T. C. Loh, D. W. Choe, and R. A. Rahim. 2014. Prevalence of antibiotic resistance in lactic acid bacteria isolated from the faeces of broiler chicken in Malaysia. Gut Pathog. 6:1-7.

Soccoll, C. R., L. P. de Souza Vandenberghe, M. R. Spier, A. B. Pedroni Medeiros, C. T. Yamaguishi, J. D. Lindner, A. Pandey, and V. Thomaz-Soccoll. 2010. The potential of probiotics: A Review. Food Technol. Biotechnol. 48:413-434.

Spano, G., P. Russo, A. Lonvaud-Funel, P. Lucas, H. Alexandre, C. Grandvalet, E. Coton, M. Coton, L. Barnavon, B. Bach, F. Rattray, A. Bunte, C. Magni, V. Ladero, M. Alvarez, M. Fernandez, P. Lopez, P. F. de Palencia, A. Corbi, H. Trip, and J. S. Lolkema. 2010. Biogenic amines in fermented foods. Eur. J. Clin. Nutr. 64(Suppl. 3):S95-S100.

Šušković, J., B. Kos, J. Beganović, A. Leboš, K. Habjanič, and S. Matošić. 2010. Antimicrobial activity - The most important property of probiotic and starter lactic acid bacteria. Food Technol. Biotechnol. 48:296-307.

Tagg, J. R., and A. R. McGiven. 1971. Assay system for bacteriocins. Appl. Microbiol. 21:943.

Taranto, M. P., A. P. de Ruiz Holgado, and G. F. de Valdez. 1995. Bile salt hydrolase activity in Enterococcus faecium strains. Microbiol. Aliment. Nutr. 13:375-379.

Todorova, S. D., H. Nyati, M. Meincken, and L. M. T. Dicks. 2007. Partial characterization of bacteriocin AMA-K, produced by Lactobacillus plantarum AMA-K isolated from naturally fermented milk from Zimbabwe. Food Control 18:656-664.

Üstün, M., B. Özden, Ö. Şimşek, and M. Akçelik. 2009. Identification of Lactococcus lactis ssp. lactis based on their cell wall protein and plasmid contents. Turk. J. Biol. 33:21-27.

Viana de Souza, J., and F. Silva Dias. 2017. Protective, technological, and functional properties of select autochthonous lactic acid bacteria from goat dairy products. Curr. Opin. Food Sci. 13:1-9. 
Vinderola, C. G., and J. A. Reinheimer. 2003. Lactic acid starter and probiotic bacteria: a comparative "in vitro" study of probiotic characteristics and biological barrier resistance. Food Res. Int. 36:895-904.

Ward, L. J. H., G. P. Davey, H. A. Heap, and W. J. Kelly. 2002. Lactococcus lactis. Pages 1511-1516 in Encyclopedia of Dairy Sciences. H. Roginski, J. W. Fuquay, and P. F Fox, ed. Elsevier Science Ltd., London, UK.

Warminska-Radyo, I., L. Laniewska-Moroz, and A. Babuchowski. 2002. Possibilities for stimulation of Bifidobacterium growth by propionibacteria. Lait 82:113-121.

Wikler, M. A. 2006. Performance standards for antimicrobial susceptibility testing: Sixteenth informational supplement. Clinical and Laboratory Standards Institute, Wayne, PA.
Yadav, K., A. Bhardwaj, G. Kaur, R. Iyer, S. De, and R. K. Malik. 2009. Potential of Lactococcus lactis as a probiotic and functional lactic acid bacteria in dairy industry. Int. J. Probiotics Prebiotics $4: 219-228$.

Yadav, R., A. K. Puniya, and P. Shukla. 2016. Probiotic properties of Lactobacillus plantarum RYPR1 from an indigenous fermented beverage raabadi. Front. Microbiol. 7:1683.

Zendo, T., M. Fukao, K. Ueda, T. Higuchi, J. Nakayama, and K. Sonomoto. 2003. Identification of the lantibiotic nisin Q, a new natural variant produced by Lactococcus lactis 61-14 isolated from a river in Japanese. Biosci. Biotechnol. Biochem. 67:1616-1619. 